\title{
EFÍMERO RESTABLECIMIENTO EN LA CORUÑA DE UNA ANTIGUA CÁTEDRA DE LATINIDAD (1840-1845)
}

\author{
Por \\ ANTONIO MEIJIDE PARDO
}

La primordial fuente documentativa que nos ha permitido elaborar el presente artículo atañe, fundamentalmente, a los libros de Acuerdos del Ayuntamiento coruñés y a un amplio dossier de papeles inéditos, conservado igualmente en el Archivo Municipal, con el siguiente epígrafe: $E x$ pediente sobre el restablecimiento de la Cátedra de Gramática Latina que existía en el Convento de San Francisco de esta Ciudad, e investigación de las rentas asignadas a su sostenimiento ${ }^{1}$.

Preciso es, previamente, anotar que esta Escuela de Latinidad estuvo tutelada desde mediados del siglo XVI por los Jesuitas. La Colegiata de Santa María y el Ayuntamiento ajustaron entonces su fundación con el designio de que «los niños, y otras personas, no tuviesen necesidad de ir a otras partes...», y aplicarse así «de mayor gana al estudio», para que pudiesen algunos «llegar a ser grandes hombres, así en lo espiritual como en lo temporal». Como cláusulas sustantivas de esta peculiar fundación docente citemos, entre otras, las siguientes:

\footnotetext{
${ }^{1}$ De la información procedente de otros fondos archivísticos se da referencia con estas siglas: A.C.C. (Archivo Colegiata, La Coruña); A.U.S. (Archivo Universidad, Santiago); B.N.M. (Biblioteca Nacional, Madrid).
}

"CUADERNOS DE ESTUDIOS GALLEGOS", Tomo XLIV, Fascículo 109, Santiago 1997. 
«Para proveer la Cátedra se convocaría a pública oposición mediante edictos. El tribunal sería designado paritariamente por el Ayuntamiento y por el Cabildo, y lo presidirán el Corregidor y el Juez eclesiástico. Para el control de los estudios, cada corporación designaría anualmente un comisario o delegado, que hará las veces de visitador. El catedrático leería, de balde, a todos los que acudiesen, percibiendo por ello la renta de 6.000 maravedies que aportaría el Municipio, más una prebenda y casas para vivienda y aulas, proporcionadas por el Cabildo» ${ }^{2}$.

Indiquemos también que la referida Cátedra fue reestructurada en su vertiente económica en 1679 , en virtud de otro convenio ajustado ahora entre la Colegiata y la Compañía de Jesús; por el que su mantenimiento correría a cargo de las dos terceras partes de los diezmos del curato de San Pedro de Visma, parroquia enclavada en los arrabales de la Ciudad ${ }^{3}$.

Consignemos, en fin, que el también nominado Estudio Público de Gramática, instalado en el convento de San Francisco, subsistió en ejercicio hasta 1835. En cuyo año, y en virtud de producirse la exclaustración de las comunidades religiosas, siendo Alvárez Mendizábal primer ministro de Isabel II, fue decretada su extinción; este hecho transcendental conllevaría más tarde la venta por el Estado de los cuantiosos bienes del clero regular.

Fue en 1837 — cumplido un bienio de esta famosa y audaz ley de desamortización eclesial — cuando se dieron los primeros pasos por el Ayuntamiento en pro de recuperar para la juventud estudiosa la enseñanza tradicional del Latín con la reposición de la antigua Cátedra; la cual ahora no sería costeada y tutelada por la Iglesia, sino por la Municipalidad. Y las primerizas providencias a fin de recuperar tan importante logro educativo, consistieron en realizar toda suerte de indagaciones en orden a procurar el apronto de los recursos indispensables para el mentado intento. Hiciéronse, en tal sentido, numerosas pesquisas para averiguar «los arrendamientos por frutos en grano, manteca, cera, gallinas y de otras

\footnotetext{
${ }^{2}$ E. Rivera Vázquez, Galicia y los Jesuitas. Sus colegios y enseñanzas en los siglos XVI al XVIII, pág. 412 (La Coruña, 1989).

${ }^{3}$ A.C.C., Actas Capitulares, lib. 3, fols. 393-397, etc.

A.M.C., Instrucción Pública, doc. 24 jun. 1837, etc.

"CUADERNOS DE ESTUDIOS GALLEGOS", Tomo XLIV, Fascículo 109, Santiago 1997.
} 
especies»; producto del que habían gozado anteriormente conventos y prioratos de la ciudad y su provincia, ahora suprimidos por la supradicha ley de Mendizábal ${ }^{4}$.

Una vez concluida esta tarea investigativa, la Municipalidad se apresuró a solicitar del Gobierno la competente facultad para disponer de las citadas rentas eclesiásticas. Y muy especialmente de los diezmos o sinecura de San Pedro de Visma, considerados como básicos para dotar a la Cátedra de Latinidad que se pretendía restablecer 5 .

Transcurridos dos años sin que por el Gobierno fuese dictada providencia alguna sobre las peticiones formuladas desde 1837, en 1839 se intensificaron notablemente los esfuerzos coruñeses; ejercía ahora el cargo de Corregidor Vicente Alsina Selisis ${ }^{6}$, quien no se dio punto de reposo a efectos de reinstaurar, bajo patrocinio municipal, la vieja Cátedra de Latinidad.

Pero antes, no debemos omitir que el Gobierno tenía en perspectiva la promulgación de una nueva ley general de enseñanza a todos los niveles. Obsérvase, en este contexto, que en 14 de mayo de 1839 la Junta Provincial de Instrucción Pública inquiere del Ayuntamiento noticia circunstanciada relativa a los centros de enseñanza, así primaria como secundaria, sostenidos en virtud de fundaciones, patronatos o legados particulares de diversa índole.

Con respecto a la Cátedra de Latinidad, la corporación municipal significará a la Junta que el hecho de no haberse restablecido, no estaba motivado por la carencia de un local para su instalación, sino que obedecía únicamente a la consecución de los fondos necesarios para su dotación, y a las diferencias suscitadas con la Dirección General de Rentas sobre este particular. Se expresa asimismo hallarse sub judice la reclamación alzada por el Concejo tocante al cobro de 400 ducados anuales que, como carga de justicia, mandó satisfacer la Real Hacienda para el indicado fin; vale decir, «el completo de las dos terceras partes de los diezmos de San Pedro de Visma, cuya reclamación de los 400 ducados se entiende desde la extinción de los frailes en $1835 »^{7}$.

\footnotetext{
${ }^{4}$ A.M.C., Ibidem., docs. 13 jun. y 26 ago. 1837.

${ }^{5}$ Vid. Apéndices núms. 2 y 3.

${ }^{6}$ Sobre V. Alsina, político de ideología liberal y un acreditado hombre de negocios, recientemente aportó información en sendas obras A. González Catoira: Biografías coruñesas (págs. 20-32) y Alcaldes coruñeses (págs. 17-22).

${ }^{7}$ A.C.C., Actas Capitulares, lib. 16, ses. 5 jul. 1839, etc.

"CUADERNOS DE ESTUDIOS GALLEGOS", Tomo XLIV, Fascículo 109, Santiago 1997.
} 
Después de constatarse, fehacientemente, que el principal arbitrio económico para poder restablecer la Cátedra de Latinidad incumbiría a los diezmos de la parroquia suburbana de Visma, vemos que el Jefe Político Superior de la Provincia requería al Cabildo de la Colegiata de Santa María del Campo, para que se aprontaran los 50 ducados anuales que se satisfacían a los PP. Jesuitas por mantener dicha Cátedra, de conformidad a lo prescripto por la escritura notarial que ajustaron en 1800 la Colegiata y la Compañía de Jesús ${ }^{8}$.

Como último dato hay que añadir que en el consistorio municipal de 21 de septiembre de 1839 dábase lectura a un dictamen de la Contaduría de Amortizaciones Eclesiásticas, manifestando no existir inconveniente alguno para que el gobierno local pueda percibir 8.800 reales, como producto de las dos tercias partes de los diezmos propios del curato de Visma y correspondientes al bienio 1835-36. Semanas después de haber sido remesada la referida cantidad, también ingresarían en Depositaría 3.089 reales de los frutos de Visma atinentes a $1837^{\circ}$.

Así pues, asegurada ya la mínima cobertura económica de esta Escuela de Gramática Latina, quedan ahora por resolver otras dos importantes cuestiones: local donde aquélla habría de instalarse y nominación del Preceptor de estudios. Por lo que respecta al aula, se acordó utilizar, provisionalmente, una sala de la propia Casa consistorial (en la cual se hicieron, con un coste de 4.000 reales, obras de reparación dirigidas por el arquitecto municipal J.M ${ }^{a}$ de Noya). Una vez concluido el acondicionamiento del local, y deseoso el Ayuntamiento de que «el público no pierda por más tiempo el goce y utilidad» del nuevo centro docente, en el otoño del 39 convocábase la provisión, con carácter de interinidad, de la plaza de Preceptor. A cuyo efecto, hizo público la Alcaldía el siguiente anuncio:

«Habiendo de restablecerse con la competente autorización la Cátedra de Latinidad que existía antes de ahora en el suprimido convento de San Francisco, ha acordado el Ayuntamiento provistar interinamente la plaza de Preceptor, cuya dotación será por ahora de cuatro mil reales, sin perjuicio de las retribuiciones que el Reglamento prescribe.

\footnotetext{
${ }^{8}$ A.M.C., Acuerdos, 1839 , fols. 196 y 224

${ }^{9}$ A.M.C., Ibidem, fols. 239 y 370.
} 
«Los ramos que han de abrazar las enseñanzas son los siguientes: El conocimiento exacto de todas las partes de la oración, sus oficios, accidentes y propiedades. La declinación de los nombres latinos y grecolatinos, con la conjugación de los versos regulares e irregulares en todas direcciones. Un tratado completo de todas las clases de oraciones. Otro del idiotismo y particular del castellano con su correspondencia en latín. La sintaxis natural, figurada y elegante. La prosa y arte métrica. La ortografía. El ejercicio y propiedad de ambas versiones. Un ligero conocimiento de la mitología pagana. Un breve compendio de los principales tropos y figuras retóricas» ${ }^{10}$.

Estaba reglado que el nombramiento de Preceptor habría de verificarse por rigurosa oposición ante la Subdelegación que la Real Academia Greco-Latina, de Madrid, tuviere establecida en La Coruña. Para atender a tan importante requisito, el Alcalde Vicente Alsina solicitó del Jefe Político Superior de la provincia «se sirva decirle quienes son los individuos que componen dicha Subdelegación». Al expresarle la máxima autoridad provincial «no haber llegado el caso de establecerse en esta Provincia» la referida Subdelegación, demandó entonces el Corregidor le diese permiso - el cual obtuvo- para designar por su cuenta a personas inteligentes que se encargaran de calificar los méritos de los aspirantes a desempeñar la plaza de profesor ${ }^{11}$. A finales de octubre quedó constituido el tribunal, integrado por sendos maestros de Humanidades, Juan Nepomuceno Gil y Quirico Vázquez Pardo, y por el rector de la parroquia coruñesa de Santiago, Pedro Vilariño ${ }^{12}$.

Solamente dos candidatos solicitaron ser admitidos al examen para provistar la plaza de Preceptor. Fueron el presbítero Manuel Alvedro, natural y patrimonial de la feligresía de San Pedro de Visma, y el fraile secularizado Ángel Rosendo de Soto, quien tuvo ya a su cargo durante buenos años, declara, la Cátedra de Latinidad en el convento de San Francisco, hasta que en 1835 fue extinguida por la ley de Mendizábal.

${ }^{10}$ Boletín Oficial de la Provincia, núm. 176 (4 nov. 1839).

${ }^{11}$ A.M.C., Instrucción Pública, docs. 24 sep. y 25 oct. 1839.

${ }^{12}$ Alvariño, en razón de «no considerarse con los conocimientos necesarios», manifestó el Acalde un deseo de excusarse como miembro del tribunal; aunque, dícele, «si todavía se insistiere en ello concurrirá gustoso». El párroco accedió finalmente a participar en el examen de los pretendientes, tras expresarle Alsina que le juzgaba por «muy útil y capaz para el desempeño del cargo de examinador», esperando por tanto que «le honrará con su asistencia» (A.M.C., Acuerdos, fols. 352, 403 y 410).

"CUADERNOS DE ESTUDIOS GALLEGOS", Tomo XLIV, Fascículo 109, Santiago 1997. 
Las pruebas de oposición para ambos aspirantes - que el Concejo dispuso verificarlas «a puerta abierta para que las presenciasen todos los que gustaren...»-, tuvieron lugar el 9 de noviembre. Sucedió entonces que De Soto, sabedor de que el otro opositor carecía de título en Humanidades, «al paso que él lo tenía y había desempeñado por muchos años aquella facultad», expuso al tribunal que declinaba efectuar los ejercicios; porque «de ninguna manera entraba en examen comparativo con otro opositor que no estuviese habilitado por la ley para desempeñar el magisterio de Latinidad...» ${ }^{13}$. Presentes en este lance el presidente y dos miembros de la Comisión municipal de Instrucción Pública ${ }^{14}$, éstos le hicieron a De Soto algunas reflexiones para demostrarle que «no era el momento de entrar en tal cuestión, ni podía oírsele acerca de ella, y si quería examinarse lo dijese, y sino que podía retirarse». Y así lo verificó, tras protestar del acto $^{15}$.

Consiguientemente, Manuel Alvedro quedó como único opositor. En una certificación, rubricada horas después por la referida Comisión de I. Pública, hacíase constar cómo aquél fue examinado por el tribunal, «ya a mediación de preguntas que le hicieron los examinadores, ya traduciendo algunos trozos del autor clásico Virgilio, e ya, finalmente, vertiendo y escribiendo, en idioma castellano, algunos puntos de Quinto Curcio».

He aquí la resolución, no muy clarificadora, adoptada por los componentes del tribunal:

«No habiéndose presentado al ejercicio que debía celebrarse más que el Presbitero dn. Manuel Alvedro, el Rector de Santiago dice que habiendo sido llamado para juzgar comparativamente, y no para examinar a determinada persona, se abstiene por ahora de emitir voto en la materia. Dn. Quirico Vázquez Pardo, atendiendo al ejercicio del referido Presbítero, opina que su aptitud se reduce a poder desempe-

\footnotetext{
${ }^{13}$ En 1825, a instancias de la Real Academia latina Matritense, dispuso una real orden que para «ser admitido a examen cualquier profesor de Latinidad, ha de acreditar haber ejercido con otro y aprobado dos años de pasantía», o en su defecto estar graduado de Bachiller en Facultad Mayor (B.N.M., Varios especiales, 1.063/100. Cfr. Apéndice núm. 1).

${ }^{14}$ J.M. de Prado, $3^{\circ}$ Alcalde, R. Bernández, regidor, y J.B. de Castro, síndico.

${ }^{15}$ A.M.C., Instrucción Pública, doc. 10 dic. 1839.
}

"CUADERNOS DE ESTUDIOS GALLEGOS", Tomo XLIV, Fascículo 109, Santiago 1997. 
ñar las funciones de Ayudante de un Profesor y bajo la inmediata dirección de éste, pero de ningún modo para desempeñar una Cátedra y, señaladamente, en una capital de Provincia de primera clase. $Y$ dn. Juan Nepomuceno Gil opina del mismo modo que el Sr. Rector» ${ }^{16}$.

Del dictamen antecedente se infiere cómo fue puesta en tela de juicio la capacidad, como enseñante de garantía, del único aspirante a cubrir la plaza de Preceptor. Y vemos, en este contexto, cómo optaría la Comisión de Instrucción Pública por proponer al Ayuntamiento, que «se debía dejar instalada la Cátedra de Latinidad, y que ésta podía provistarse interinamente en Dn. Quirico Vázquez Pardo, sujeto que reunía las circunstancias necesarias para su desempeño» ${ }^{17}$. El texto del dictamen elevado por dicha Comisión al Corregidor decía como sigue:

«En cumplimiento de lo acordado por V.S.Y., terminante a que los individuos de la Comisión encargada de presidir el examen para Catedrático de Latinidad, examinaran los títulos y más documentos de que hizo presentación dn. Quirico Vázquez Pardo, y dijeren en su visita si tenía la aptitud para desempeñar aquel cargo, hemos visto los que nos exhibió el referido Vázquez, comprensivos:

$1^{\circ}$. Del título de Profesor de Latinidad expedido por acuerdo de la Inspección general de Instrucción pública en 27 de Abril de 1832, después de haber sido examinado y aprobado por el Colegio de Lenguas de la Universidad de Santiago, concediéndole el permiso de abrir estudio público para enseñar el idioma latino en todas las Ciudades, Villas y Lugares de las Provincias de España.

$2^{\circ}$. Del grado de Bachiller en Filosofía, de mérito, que se le confirió, nemine discrepante, en 6 de Mayo de 1801.

$3^{\circ}$. Del título de Bachiller en Leyes, a claustro pleno, en $3^{\circ}$ año, también de mérito, que se le confirió en 25 de Julio de 1804.

$4^{\circ}$. Del título de Bachiller en Cánones, que se le ha conferido en 6 de Octubre de 1807.

\footnotetext{
${ }^{16}$ A.M.C., Ibidem, doc. cit.

${ }^{17}$ A.M.C., Acuerdos, fols. 434 y 438.
}

"CUADERNOS DE ESTUDIOS GALLEGOS", Tomo XLIV, Fascículo 109, Santiago 1997. 


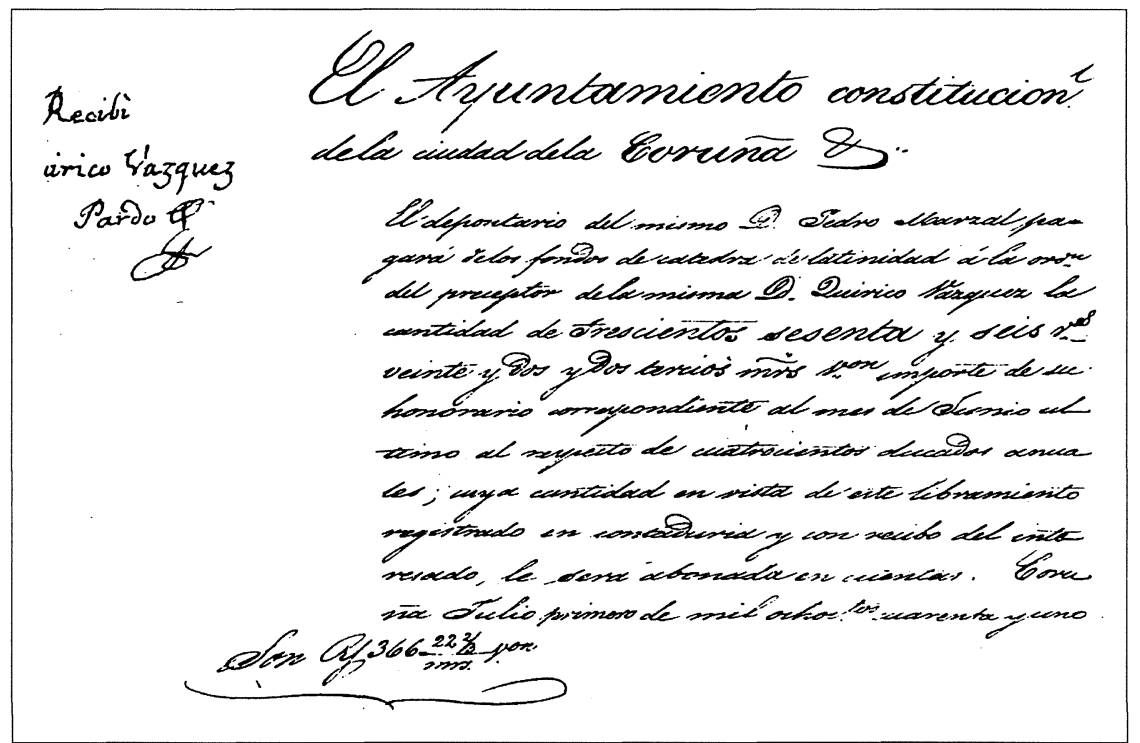

El Concejo coruñés dispone se abonen al profesor Vázquez Pardo sus haberes de junio de 1841 .

$5^{\circ}$. Dos certificaciones de los Doctores y Catedráticos dn. José González Bermúdez y el Canónigo Doctoral dn. Francisco Xavier Valdivieso y Caamaño, por los que se acredita haber concluido con distinción, el sobredicho, la carrera Canónica.

$6^{\circ}$. De un certificado del Doctor dn. José Fermín del Muro, abogado del Ylustre Colegio de esta Ciudad, dado en 31 de Octubre de 1837, por el que consta haber concluido la práctica forense.

Por consecuencia de la exhibición que nos hizo de los expresados documentos, y del examen y justo aprecio que de ellos hemos hecho consideración, consideramos que no sólo tiene la suficiente aptitud para regentar la Cátedra, sino que por sus superiores méritos debe el Ayuntamiento congratularse, y recomendarle, si cabe, a la Academia de Ciencias para la propiedad de dicha Cátedra» ${ }^{18}$.

${ }^{18}$ A.M.C., Instrucción Pública, doc. 31 dic. 1839.

$\mathrm{Al}$ antecedente historial de méritos de Vázquez Pardo (natural de Betanzos, 1780), cabe añadir que en 1850 obtendría en la Universidad compostelana el título de Regente de $2^{\text {a }}$ clase, que le permitía impartir enseñanza en Colegios Privados e incluso en Institutos (A.U.S., Expedientes, leg. 1.539).

"CUADERNOS DE ESTUDIOS GALLEGOS", Tomo XLIV, Fascículo 109, Santiago 1997. 
En enero de 1840, ya ratificado el nombramiento de Vázquez Pardo como Preceptor, se anunció en edicto público la apertura de matrícula para el alumnado. Para el que fue primer curso académico, se inscribieron 21 escolares, de edades comprendidas entre 10 y 14 años; 18 de éstos eran hijos de familias acomodadas y los restantes de las conceptuadas como pobres. Matrícula muy poco acorde con relación al censo de la ciudad, del orden de los 20.000 habitantes.

El 2 de febrero tuvo lugar con toda solemnidad el acto de apertura de la Cátedra de Latinidad. En el consistorio celebrado al día siguiente por el Ayuntamiento se pormenoriza dicho evento como sigue:

«Reunidos los Señores del márgen a las doce y media en punto de la mañana en la Sala Consistorial, dispuso el Señor Presidente la entrada de todas las personas que se hallaban fuera, incluso-dn. Quirico Vázquez Pardo, profesor y regente interino de la Cátedra de Latinidad.

Y habiéndose verificado, el Señor Presidente pronunció un discurso, en el que ha manifestado todos los pasos dados por la Corporación municipal el año anterior, los esfuerzos de su digno Presidente para poner en claro las rentas anexas a dicha Cátedra y los demás que fueron consiguientes para la provisión interina del Catedrático; jurando seguidamente en sus manos dicho profesor de guardar la Constitución política de 1837, ser fiel a la Reyna, y desempeñar con el mayor esmero y exactitud la enseñanza que iba a confiársele; dándole en el acto posesión formal, y entregándole como signo de ella el pliego de matrícula de los alumnos que hasta el día se presentaron a inscribirse.

El profesor interino inauguró un discurso, en el que ha demostrado la utilidad de la enseñanza de la lengua latina, como base preliminar de todas las ciencias, y también las cualidades de que debe estar dotado un maestro; y declarando el Ayuntamiento que mañana es el primer día lectivo, de que se enteró el profesor, se retiró éste y todas las personas concurrentes» ${ }^{19}$.

\footnotetext{
${ }^{19}$ A.M.C., Acuerdos, fols. 53-54.

"CUADERNOS DE ESTUDIOS GALLEGOS", Tomo XLIV, Fascículo 109, Santiago 1997.
} 


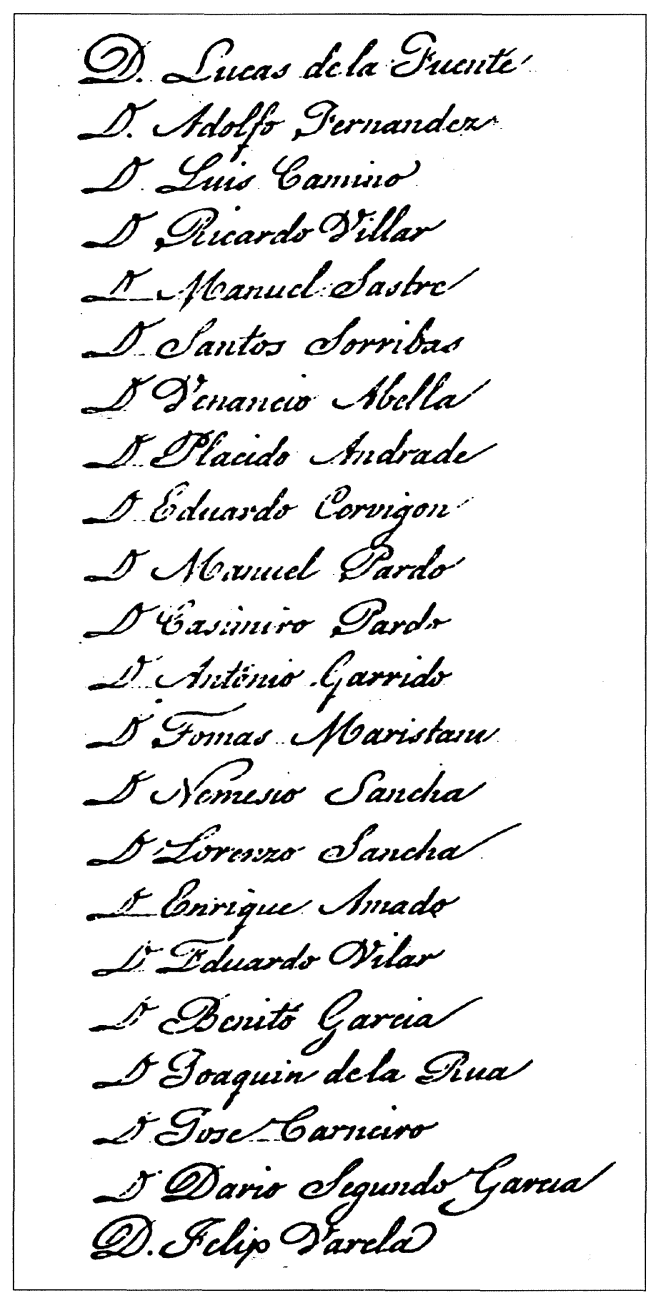

Relación de alumnos matriculados en la Cátedra de Latinidad durante el curso académico 1841-42.

Anotemos ahora que los exámenes de final de curso (éstos comportaban, curiosa nota distintiva, un acto abierto al público) solían celebrarse a mediados de octubre, y tenían por escenario el salón de sesiones del Concejo o un aula cedida por la Junta de Comercio. En cuanto al temario del examen final, copiamos a guisa de ejemplo el atinente al curso académico de 1845-46:

"CUADERNOS DE ESTUDIOS GALLEGOS", Tomo XLIV, Fascículo 109, Santiago 1997. 
"Los alumnos de la $4^{a}$ sección y de la segunda clase, presentarán a los señores concurrentes el tomo $2^{\circ}$ de la colección de autores latinos, que contiene la guerra Catilinaria escrita por Salustio, dos libros de la guerra Púnica de Tito Livio y seis oraciones de Cicerón, para que, a su arbitrio, les señalen el pasaje que deben traducir; ejecutando lo mismo con la Historia de Alejandro el Grande escrita por Quinto Curcio, las elegías de Tibulo y Catulo, los epigramas de Marcial, y la Eneida de Virgilio, que es la colección de poetas contenidos en el $3^{\circ}$ tomo, los Tristes y el Ponto de Ovidio; haciendo la competente análisis etimológica y de sintaxis; después de haberse retirado en breve rato a repasar, y saliendo uno a uno a traducir el pasaje que les haya tocado, medirán cualquier verso que se les mande de los indicados poetas, aplicando las reglas de prosodia» ${ }^{20}$.

Por lo que concierne al profesorado, no hay que omitir que otro maestro de latinidad, el coruñés Juan Nicasio Alvárez ${ }^{21}$, solicitó del Ayuntamiento, desde finales de 1840, fuese también provistada, a su favor, la plaza de Ayudante (o segundo Preceptor). Fundamentaba tal petición en que, habiéndose matriculado más de 20 alumnos, el Reglamento de la Cátedra prescribía fuese compartida por dos profesores la labor docente, uno Regente y otro Ayudante, a los que se les asignaba un sueldo de 400 y 300 ducados anuales, respectivamente ${ }^{22}$. En 1841 y 1842 reiteraría Alvárez esta pretensión. Infructuosamente, porque el crítico estado de los fondos municipales hacía imposible cubrir la segunda plaza. La Comisión de Instrucción Pública, por otra parte, hacía ver al Corregidor que el trabajo desempeñado por un solo profesor proporcionaba un ahorro de 300 ducados $^{23}$.

Obvio es que las penurias de índole económica han condicionado obstantivamente a esta Escuela de Gramática Latina en su corta etapa de vida, de apenas un sexenio. He aquí un par de datos, harto significativos,

\footnotetext{
${ }^{20}$ Boletín Oficial de la Provincia, núm. 166 (17 oct. 1845).

${ }^{21}$ Alvárez, con sendas titulaciones de Preceptor de Humanidades y Bachiller en Filosofía, formó parte durante el curso académico 45-46 del plantel docente de un Colegio Privado de $2^{a}$ Enseñanza, instalado en la calle de la Contaduría.

${ }^{22}$ Véase Apéndice núm. 4 (artículos 2, 6 y 26).

${ }^{23}$ A.M.C., Acuerdos, 1841 y 142, fols. 15 y 38. Instrucción Pública, docs. 23 nov. 1840 y 26 jul. 1842 .
}

"CUADERNOS DE ESTUDIOS GALLEGOS", Tomo XLIV, Fascículo 109, Santiago 1997. 
del año 1841: en agosto, la Comisión de Hacienda hacía saber al Concejo que apenas ascendía el fondo disponible a 1.230 reales, de suerte que era muy de temer que «podía llegar el día en que no haya con que satisfacer el honorario del Preceptor»; en octubre, informará de nuevo dicha Comisión que la Depositaría sólo disponía de dinero para abonar «la mensualidad corriente del Preceptor y diez días de otras» ${ }^{24}$.

Independientemente de esta flaqueza de recursos, también se contempla cómo la Comisión de Instrucción Pública criticó con severidad «el mal estado orgánico y administrativo» de la Cátedra. El Alcalde comisionó entonces a los ediles Fontenla y Vilela para realizar las necesarias reformas con objeto de mejorar el régimen interior y, sobre todo, corregir ciertas irregularidades en las que habría incurrido Vázquez Pardo, único encargado de la enseñanza, y otros considerandos; siendo una de las anomalías detectadas la de percibir aquél sus retribuciones mensuales directamente de los alumnos ${ }^{25}$.

Conviene significar que a partir de septiembre de 1845 , y a consecuencia de promulgar el Gobierno el nuevo Plan General de Estudios de $2^{a}$ Enseñanza, comenzó a ser puesta en entredicho la perdurabilidad de la Cátedra de Latinidad. Fruto, sin duda, del criterio político sustentado por el ministerio progresista de Pérez de Castro, obvio es que el citado Plan no tuvo otro designio que el de estorbar, en lo sucesivo y lo más posible, la creación de nuevos centros docentes auspiciados por la Iglesia o promovidos por patronatos o mecenazgos de carácter privado. Y sí el de favorecer, en contrapartida, a los llamados Institutos de $2^{\circ}$ Enseñanza, bajo marchamo oficial, cuyo número comenzará a proliferar en años sucesivos $^{26}$.

Así pues, bien se contemplaba ahora la imposibilidad de que esta Cátedra costeada por el Ayuntamiento prosiguiera en ejercicio, por considerarla incompatible con el espíritu y la letra del citado decreto, que impuso

${ }^{24}$ A.M.C., Acuerdos, 1841 , fols. 181 y 222.

${ }^{25}$ A.M.C., Ibid., 1841 (276) y 1842 (197 y 207). Apéndice núm. 5.

${ }^{26}$ Cfr. mi libro: Eusebio da Guarda y el Instituto de $2^{a}$ Enseñanza de La Coruña, págs. 83-84 (La Coruña, 1991).

Indiquemos, de pasada, que los primeros Institutos creados en Galicia, lo fueron en Lugo (1842), Santiago, Ourense y Pontevedra (1845), Monforte (1848) y La Coruña (1862).

"CUADERNOS DE ESTUDIOS GALLEGOS", Tomo XLIV, Fascículo 109, Santiago 1997. 
una reforma sustancial de todo el sistema educativo de tipo medio. Por consiguiente, con data 2 de diciembre, decidía el Ayuntamiento notificar al Jefe Político Superior de la Provincia (José Martínez) sobre la próxima supresión de la Cátedra.

Sin embargo, sorprendentemente, vemos semanas después que en modo alguno daría su placet el Jefe Político a la decisión acordada por la Municipalidad. Así lo expresará al Alcalde (Francisco Sangro) por medio del siguiente comunicado:

«La adopción de una medida de esta especie, tan transcendental e importante para la instrucción pública, creo debió ser objeto, por parte de ese Ayuntamiento, de un muy detenido examen, y de ningún modo llevarla a efecto sin la aprobación de este Gobierno Político, requisitoria indispensable según el art ${ }^{\circ} 81$ de la Ley de Ayuntamientos, siempre que se trate de suprimir establecimientos municipales. Deseoso yo de acordar en el particular lo más legal y conveniente para el público, he pedido informe al Consejo Provincial de Administración y, de acuerdo con su ilustrado dictamen, he determinado:

$1^{\circ}$. Declarar ineficaz, y dejar sin efecto, el acuerdo del Ayuntamiento de esta Capital de 2 del próximo pasado, en cuyo concepto deberá reponerse la Cátedra de Latinidad, volviendo las cosas al mismo ser y estado que tenían antes de dicho acuerdo.

$2^{\circ}$. Que con toda urgencia me remita una relación circunstanciada de las rentas y fondos destinados al sostenimiento de dicha Cátedra, su origen y procedencias, con todos los datos y noticias existentes en el archivo municipal, y que la corporación crea son conducentes para ilustrar esta importante materia.

Todo lo cual lo digo a V.S., para que se sirva ponerlo en conocimiento de la Municipalidad en la primera sesión, a fin de que tenga el más exacto y puntual cumplimiento» ${ }^{27}$.

El Concejo, en respuesta al oficio antecedente, se limitó a remitir a la máxima autoridad provincial el amplio y fundamentado dictamen evacuado por su Comisión de Educación, y que hacía suyo. Éste iba confor-

${ }^{27}$ A.M.C., Instrucción Pública, doc. 17 ene. 1846.

"CUADERNOS DE ESTUDIOS GALLEGOS", Tomo XLIV, Fascículo 109, Santiago 1997. 
me en el sentido de considerar que la nueva ley reguladora de los estudios del Bachillerato, promulgada en septiembre de 1845, fehacientemente dejaba «muy claro e incontrovertible que la Cátedra de Latinidad había cesar...» A mayor abundamiento, entre otros extremos, prescribíase ahora que «cada provincia tendrá un Instituto, colocado en la capital», en donde se impartirá la enseñanza de Latín durante los cinco años del Bachillerato, como idioma fundamental de los estudios para el alumno que deseara seguir las carreras universitarias ${ }^{28}$.

La Cátedra de Latinidad, en definitiva, dejó de subsistir. La última información disponible en los fondos del Archivo Municipal, es la que atañe a la cuestión de conceder al exprofesor Quirico Vázquez Pardo la jubilación que «se considere justa según sus circunstancias». Al fin, casi un año después, se resolvió asignar al profesor cesante, en concepto de jubilación, la pensión anual de 2.500 reales $^{29}$.

${ }^{28}$ A.M.C., Acuerdos, 1846, fols. 2, 9 y 14. Instrucción Púb.ica, doc. 30 ene. 1846.

${ }^{29}$ A.M.C., Acuerdos, 1847, fols. 2, 8 y 12.

"CUADERNOS DE ESTUDIOS GALLEGOS", Tomo XLIV, Fascículo 109, Santiago 1997. 


\section{APÉNDICE NÚM. 1}

Algunos de los principales artículos del Reglamento para Escuelas de Latinidad promulgado en 1826.

(...)

"Art ${ }^{\circ} .3^{\circ}$ Todo Preceptor autorizado para enseñar públicamente la lengua latina, podrá abrir Escuela en los pueblos habilitados, observando las condiciones siguientes:

$1^{a}$. Ha de obtener el permiso de la Justicia y Ayuntamiento, quienes no podrán negarle siempre que el Pretendiente presente su título y la correspondiente justificación. $2^{\mathrm{a}}$. Ha de conformarse con lo prevenido en este Reglamento, así en cuanto a los libros por donde enseñe como en orden al mérito de enseñanza. $3^{a}$. No ha de enseñar otra ciencia o facultad, pero si sabe griego podrá dar a sus discípulos algunos principios de esta lengua.

$\mathrm{Art}^{\circ} .4^{\circ}$. El Preceptor que observando estas condiciones establezca Escuela de Latinidad, podrá admitir en ella pupilos, medio pupilos y descípulos externos, y exigir de todos ellos la retribución en que se conviniere con sus padres y tutores.

(...)

$\mathrm{Art}^{\circ} .10^{\circ}$. Todas las Escuelas de Latinidad, a no ser las de los Colegios y Seminarios, las de los Padres Jesuitas y Escolapios, y las de fundación piadosa establecidas en Conventos y Casas de Regulares, estarán en la parte literaria bajo inspección de las Universidades respectivas más inmediatas.

(...)

$\operatorname{Art}^{\circ} .12^{\circ}$. En estas Escuelas se enseñará: $1^{\circ}$. La Gramática de la lengua latina en toda su extensión. $2^{\circ}$. Paralela y comparativamente la Gramática castellana. $3^{\circ}$. Traducir correctamente del latín al español, y de éste al latín. $4^{\circ}$. Un tratadito de antigüedades romanas, otro de Mitología, o como suele decirse, de los tropos o figuras de significación.

$\mathrm{Art}^{\circ} .13^{\circ}$. Los libros de que, por ahora, se harán uso serán los siguientes: La Gramática latina del P. Carrillo o la de los Padres Escolapios de la provincia de Castilla, y la castellana de la Real Academia Española. Para traducir del latín al castellano, la Colección de Autores, usada en las Escuelas Pías, y el Calepino de Salas o el Diccionario manual de Jiménez. Para la Mitología, el tratadito del Padre Juvencio, traducido al castellano. Para las antigüedades romanas y los tropos dictará el Profesor unas breves lecciones, mientras no se hayan publicado los Compendios de que se habla en el artículo $110 \gg{ }^{30}$.

${ }^{30}$ A.U.S., Serie Histórica, leg. 200, mazo $2^{\circ}$.

"CUADERNOS DE ESTUdIOS GALLEGOS", Tomo XLIV, Fascículo 109, Santiago 1997. 


\section{APÉNDICE NÚM. 2}

La Comisión municipal de Instrucción Pública informa al Corregidor sobre el proyecto restablecimiento de la antigua Cátedra de Latinidad.

«Illmo. Señor:

Por efecto de la Concordia celebrado en el año de 1679 entre los Cabildos Eclesiástico y Secular con la Compañía de Jesús, al cargo de ésta se hallaba una Cátedra de Latinidad costeada a expensas de sus rentas, a las que para aquel efecto hizo cesión el Cabildo Eclesiástico de algunas en favor de la Compañía de Jesús según manifiesta la Concordia.

Extinguida la Religión de los Padres Jesuitas, de los fondos de sus Temporalidades siguió costeándose la citada Cátedra y, últimamente, se hallaba al cuidado de los Religiosos de San Francisco de esta Ciudad, que disfrutaban la dotación de 400 ducados anuales por este trabajo. Suprimidas todas las Religiones Seculares y, por consiguiente, la de San Francisco, quedó abandonada la Cátedra, y el Pueblo sin beneficio de ella.

La Comisión de Amortización es la que administra en virtud de decretos reales los bienes de las Religiones suprimidas, tomando sobre sí las cargas que a aquéllos estaban afectos. A ella es pues a quien debe realmente la pensión de que se trata, y ella es la responsable por un principio de justicia. La Religión de los Jesuitas desapareció cuando lo tuvo a bien el Gobierno del Señor D. Carlos $3^{\circ}$, dispuso de los bienes que poseían, mas reconociendo siempre las obligaciones que aquéllos traían consigo, y así es que se respetó la de la Cátedra de Latinidad, que subsistió como queda dicho. Los Gobiernos son los primeros en conservar y sostener los contratos. Uno había entre Jesuitas y Pueblo (así puede decirse). El Gobierno substituyó la parte de los primeros y cumplió hasta la época en que existieron los Religiosos de San Francisco que regentaban la Cátedra.

Al Señor Intendente debe oficiarse, según lo expuesto, con manifestación del derecho que asiste para que ponga expedito el producto de la parte de diezmos de San Pedro de Visma, que es lo que donó la Colegiata a la Compañía de Jesús para sostener la citada Cátedra, y cuyo rendimiento disfruta en la actualidad la Amortización» ${ }^{31}$

${ }^{31}$ A.M.C., Instrucción Pública, doc. 19 ene. 1837.

"CUADERNOS DE ESTUDIOS GALLEGOS", Tomo XLIV, Fascículo 109, Santiago 1997. 


\section{APÉNDICE NÚM. 3}

El Ayuntamiento solicita del ministro de la Gobernación en 1837, disponer de las dos tercias partes de los diezmos de San Pedro de Visma para sostener la Cátedra de Latinidad.

«La enseñanza de la Gramática Latina es de una conocida utilidad. Los jóvenes pobres de esta Ciudad pueden obtener esta ventaja sin dispendios, porque tienen una Cátedra gratuita costeada de las rentas de las temporalidades de los Jesuitas. La disfrutaron desde el año de 1679, en que por consecuencia de concordia entre el Cabildo de la Colegiata de esta Ciudad y la Compañía de Jesús, ésta cedió a aquél algunos bienes, y el Cabildo a la Compañía las dos terceras partes de los diezmos del curato de S. Pedro de Visma inmediata a esta Ciudad, con la obligación de sostener la Compañía dicha Cátedra. Tuvo efecto hasta la expulsión de los Jesuítas, siguió después a expensas de sus temporalidades y, últimamente, hasta la extinción de las Comunidades Religiosas, porque al cuidado de la de San Francisco se hallaba la Cátedra, abonándola con 400 ducados anuales por un convenio particular hecho con dicha Comunidad.

Cesa la Cátedra con la supresión de San Francisco, pasan las rentas de los Jesuitas a la Amortización, reclama el Ayuntamiento el producto de los diezmos para plantear la Cátedra. El Sr. Intendente no se creyó con facultad para decidir, lo eleva a la Dirección de Amortización, y por resultado sale la Real orden de 12 de abril, concediendo para este objeto los 400 ducados anuales.

(...)

La asignación de los 400 ducados podrá servir para dotación del Catedrático. Pero más se necesita. La Cátedra para plantearla causa gastos y éstos se repiten anualmente más o menos. No hay local para establecerla y si se toma una casa por alquiler es un gasto permanente.

La idea del Ayuntamiento es establecer todas las Escuelas en el Convento que fue de Agustinos en esta Ciudad. Mas el estado deplorable en que se halla este edificio, motiva no pequeños dispendios, a los que no puede atender, sino parcialmente, el Ayuntamiento, por las muchas atenciones que pesan sobre sus fondos. Y lo justo es que los propios de derecho de la Cátedra de Latinidad sean los que hayan de subvenir al gasto de plantear la Cátedra y sostenerla. Lo que se reclama no es una grande diferencia, pues serán unos 100 ducados, poco más o menos, que es lo que habrá de los 400 que se señalan al total producto de los diezmos, pero precisa por las razones expuestas para que pueda tener efecto la existencia de la Cátedra.

En tal estado el asunto, el Ayuntamiento recurre a V.E. como Jefe Superior, y verdadero protector de todos los ramos de educación, para que se sirva inclinar el ánimo de S.M. y, en uno de sus naturales rasgos de benevolencia y amor a los Españoles, conceda la gracia que pide el Ayuntamiento, de que le sea adjudicado el producto total de las dos terceras partes de los diezmos de San Pedro de Visma, para sostener la Cátedra de Latinidad conforme al espíritu del origen de la cesión de que se hace mérito, y así no quedará ilusorio su objeto como es de temer por la situación de fondos del Ayuntamiento, según se ha manifestado» ${ }^{32}$.

${ }^{32}$ A.M.C., Instrucción Pública, doc. 13 jun. 1837.

"CUADERNOS DE ESTUDIOS GALLEGOS", Tomo XLIV, Fascículo 109, Santiago 1997. 


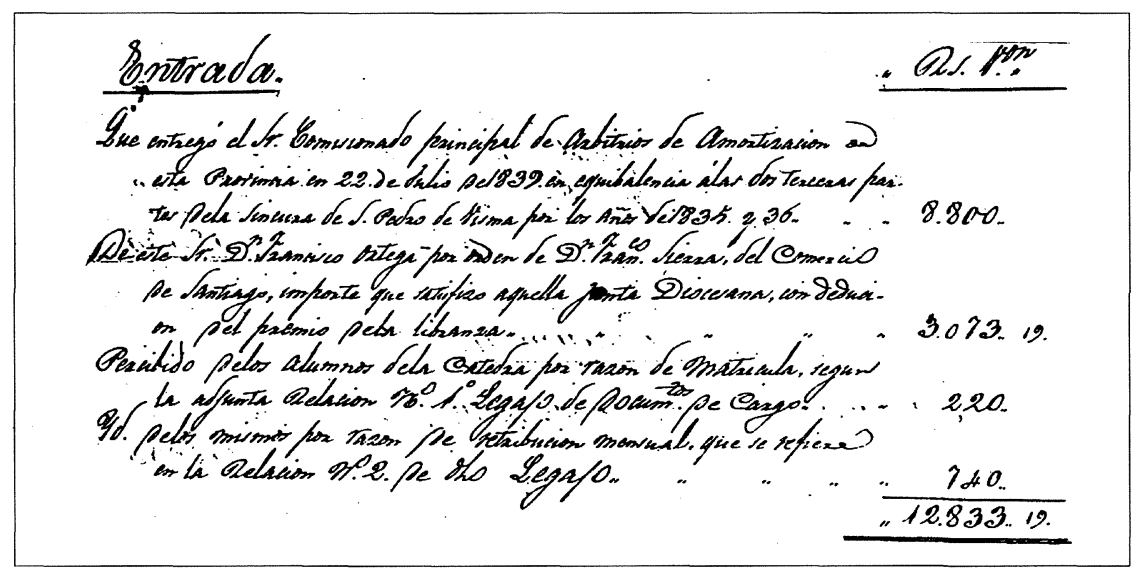

El Depositario del Ayuntamiento certifica sobre los fonsos ingresados para la Cátedra en 1840.

\section{APÉNDICE NÚM. 4}

1839. Texto del Reglamento para regir en la Cátedra de Latinidad que pretendía instituir el Ayuntamiento coruñés.

«Cátedra y Profesores de Latinidad.

$A^{\circ}{ }^{\circ}$. 1. Se restablece la Cátedra de Gramática Latina que existía antes en el suprimido Convento de San Francisco, bajo la dirección y protección del Illmo. Ayuntamiento y con arreglo a las bases siguientes.

$\mathrm{Art}^{\circ}$. 2. La enseñanza se hará por dos Profesores: el primero, que se llamará Profesor Regente, explicará a los alumnos de la segunda clase; y el segundo, que será subalterno del primero, se llamará Profesor Ayudante y explicará a los de la primera.

$\mathrm{Art}^{\circ}$. 3. A la primera clase pertenecerán los ramos siguientes:

$1^{\circ}$. El conocimiento exacto de todas las partes de la oración, sus oficios, accidentes y propiedades.

$2^{\circ}$. La declinación de los nombres latinos y greco-latinos con la conjugación de los verbos regulares e irregulares en todas direcciones.

$3^{\circ}$. Un tratado completo de todas las clases de oraciones.

$4^{\circ}$. Otro de idiotismo y particular castellano con su correspondencia en latín.

$5^{\circ}$. Deben, por último, los alumnos de esta clase saber de memoria el texto de las reglas pertenecientes a la Sintaxis, Prosodia y Ortografía.

A la segunda los que siguen:

$1^{\circ}$. La Sintaxis natural, figurada y elegante.

$2^{\circ}$. La Prosodia y arte métrica.

$3^{\circ}$. La Ortografía.

$4^{\circ}$. El ejercicio y propiedad de ambas versiones.

$5^{\circ}$. Un ligero conocimiento de Mithología Pagana.

$6^{\circ}$. Un breve compendio de los principales tropos y figuras retóricas.

"CUADERNOS DE ESTUdIOS GALLEGOS", Tomo XLIV, Fascículo 109, Santiago 1997. 
$\mathrm{Art}^{\circ}$. 4. El nombramiento de los Profesores se hará por la Autoridad a quien encarga el reglamento sobre instrucción pública de 1831, y particularmente en la Real orden de 12 de julio de 1839 .

$\mathrm{Art}^{\circ}$. 5. Los profesores de latinidad que fueren nombrados con arreglo al artículo anterior, presentados que sean para tomar posesión de sus destinos, observarán estrictamente lo que se previene en esta reglamento.

\section{Dotación y Matrículas}

$\mathrm{Art}^{\circ}$. 6. La dotación del Profesor Regente será de 400 ducados al año, y la del Profesor Ayudante de 300, que se les pagará por mensualidades vencidas. El Ayuntamiento se propone aumentar estas dotaciones hasta donde lo permitan sus fondos, siempre que el producto de sus retribuciones no les compense suficientemente, atendiendo también el mérito de los profesores en los adelantamientos que presenten los alumnos.

$\mathrm{Art}^{\circ}$. 7. Además de esta dotación fija, tendrán la eventual que den de sí las retribuciones que se marcarán, cuyo fondo se les aplicará por ahora íntegramente, percibiendo el Profesor Regente tres quintas partes, y las dos restantes el Profesor Ayudante.

Art $^{\circ}$. 8. La admisión de los alumnos se hará por el Ayuntamiento, el cual llevará un registro tanto de los ricos como de los pobres, y los que se conceptúen en esta última clase acompañarán a su instancia una certificación del cura párroco y otra del Alcalde de su barrio.

Art $^{\circ}$. 9. Los que, a juicio del Ayuntamiento, sean pobres de solemnidad nada pagarán por razón de retribución; los que no lo fuesen si pertenecen a la clase primera pagarán diez reales por mes, y quince si son de la segunda, debiendo satisfacer al tiempo de matricularse un trimestre anticipado y verificando después el pago por mes.

$\mathrm{Art}^{\circ}$. 10. Al tiempo de matricularse se exigirán también, por una sola vez al año, 10 rs. a los de primera clase y 15 a los de la segunda, que serán aplicados precisamente a costear los premios que en fin del año se han de adjudicar a los más aventajados en estudio y buena conducta. De esta contribución ni aún a los pobres se dispensa, como tampoco de la presentación de los libros de su clase.

$\mathrm{Art}^{\circ}$. 11. El profesor Ayudante llevará un libro de matrículas, en el que serán inscriptos los alumnos de ambas clases, con expresión de los nombres de sus padres o personas a cuyo cargo se hallan, de haber entregado los derechos de matrícula y presentado los libros de la asignatura o clase a que pertenezcan.

$\operatorname{Art}^{\circ}$. 12. Para que sea admitido cualquiera a la primera clase ha de saber leer y escribir correctamente, las reglas de contar por números enteros, y la doctrina cristiana. Para pasar a la segunda clase ha de estar bien cimentado en los ramos de la primera. Estos exámenes se harán por los dos Profesores, a presencia de una Comisión del Ayuntamiento.

Apertura de la Cátedra

$\mathrm{Art}^{\circ}$. 13. El día primero de Octubre se hará la apertura solemne de la Cátedra, a cuyo acto, que presidirá una Comisión del Ayuntamiento, concurrirán los dos Profesores y todos los alumnos matriculados.

Art $^{\circ}$. 14. Cada uno de los Profesores leerá o recitará un discurso escrito que comprenda dos partes. En la primera hará una explanación de los principios, máximas y doctrinas que crea más conducentes para la mejor educación de la juventud, bajo los

"CUADERNOS DE ESTUDIOS GALLEGOS", Tomo XLIV, Fascículo 109, Santiago 1997. 
aspectos religiosos, moral, civil y político, y expondrá en la segunda el métido que haciendo aplicación de estos principios se propone seguir en la enseñanza de su clase. Estos discursos será entregados a la Comisión del Ayuntamiento.

Art $^{\circ}$. 15. El Profesor Regente pasará al Ayudante una lista de todos los alumnos matriculados con expresión de las notas que obtuvieron en los últimos exámenes públicos.

Art $^{\circ}$. 16. El Profesor Regente, oyendo al Ayudante, determinará los libros de ambas clases o asignaturas, y el método de la respectiva enseñanza.

$\mathrm{Art}^{\circ}$. 17. Queda también al arbitrio del Regente determinar las horas de entrada al estudio, por mañana y tarde, que deberán ser cinco.

\section{Exámenes y Premios}

$\mathrm{Art}^{\circ}$. 18. Los días 27 y 28 de Agosto habrá exámenes públicos. Asistirán los Señores del Ayuntamiento que el mismo designare y con tres profesores de dentro o fuera de su seno, además del Regente y Ayudante, y graduarán el mérito respectivo de los alumnos, que será calificado con las tres notas de «Aprobado», «de mérito», «de sobresaliente».

$\mathrm{Art}^{\circ}$. 19. La forma de estos exámenes se fijará con un mes de anticipación por el Profesor Regente, de acuerdo con el Ayudante, y bajo la aprobación del Ayuntamiento.

$\mathrm{Art}^{\circ}$. 20. Se prepararán también en esta término los Premios que se han de adjudiar a los más aventajados, y que sin ser de mucho coste sean significativos y a propósito para despertar la emulación y robustecer el pundonor.

$\mathrm{Art}^{\circ}$. 21. De los alumnos premiados se servirán los profesores para pasantes de sus compañeros, concediéndoles preferencia y distinción en el asiento entre los de su clase y demás actos interiores de la Cátedra.

$\mathrm{Art}^{\circ}$. 22. Además de los exámenes públicos a fin de año, los habrá particulares de dos en dos meses en la forma y por el método que acuerden el Regente y su Ayudante, con conocimiento y aprobación del Ayuntamiento.

$\mathrm{Art}^{\circ}$. 23. Los sábados de cada semana, o en otro día que estime más oportuno el Regente, tendrán los alumnos exámenes y ejercicios sobre puntos de religión y moralidad, elementos de gramática castellana y breves nociones de historia y geografía, conduciéndolos con tal prudencia que miren estos ejercicios como un recreo, más bien que como fatiga, y cuidando inspirarles de paso principios de buena crianza y modales finos y corteses, y sobre todo, y con la mayor solicitud, sentimientos elevados y de amor a las instituciones políticas.

$\mathrm{Art}^{\circ}$. 24. Cuidarán también los profesores con el mayor esmero de granjearse el afecto de sus alumnos más bien que inspirarles miedo; de suerte que aún fuera del aula, tengan interés en darles gusto y cumplir sus preceptos y consejos, y nada teman tanto como incurrir en desgracia de sus maestros.

$\operatorname{Art}^{\circ}$. 25. Procurarán que se presenten aseados y limpios en su persona y vestido, que la diferencia en los trajes no exista rivalidad ni emulación, pues sólo se manifestará aprecio a las ventajas fundadas en el mérito literario, en la mayor aplicación y más arreglada conducta. Se les evitarán en lo posible las humedades y todo aquello que pueda perjudicar la salud, notificando a los padres, tutores o encargados cualquiera novedad que observen para que pongan remedio, y si estuviesen enfermos no se les permitirá la asistencia a la Cátedra, máxime siendo dolencia que pueda contagiar a los demás.

"CUADERNOS DE ESTUDIOS GALLEGOS", Tomo XLIV, Fascículo 109, Santiago 1997. 


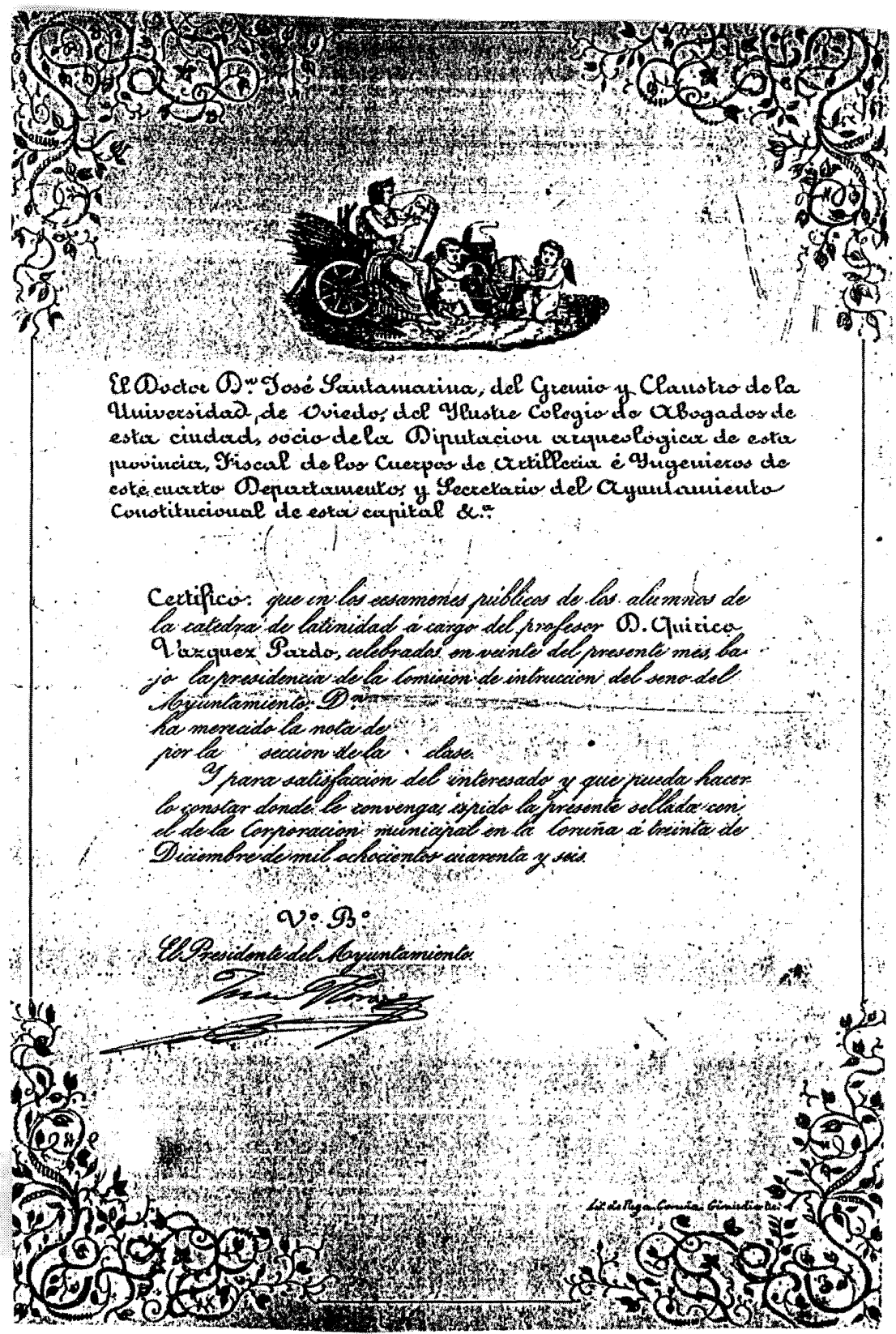

Modelo impreso del Diploma otorgado a los alumnos que aprobaban los exámenes de final de curso. 
Vacaciones y días de asueto

$\mathrm{Art}^{\circ}$. 26. Los profesores tendrán en cada año un mes de vacación, del que podrán usar cuando mejor les acomode, pero sin hacerlo a un mismo tiempo para que esté la Cátedra asistida siempre por alguno de ellos. En enfermedades y ausencia se sustituirán el uno al otro.

$\mathrm{Art}^{\circ}$. 27. Los discípulos tendrán las siguientes vacaciones y no más: de Natividad, Carnaval y Semana Santa. La primera durará desde víspera de Natividad inclusive hasta el año día del año nuevo. La segunda los tres días de Carnaval y el miércoles de Ceniza. Y la tercera vacación desde el sábado de Ramos por la tarde hasta el miércoles de Pascua.

$\mathrm{Art}^{\circ}$. 28. Serán de asueto los días de fiesta entera. El Ayuntamiento podrá conceder esta gracia aún en días que no sean de fiesta a petición de los discípulos por algún regocijo público u otro motivo especial que queda a su arbitrio y dirección.

$\mathrm{Art}^{\circ}$. 29. En los días de fiesta entera concurrirán al aula todos los alumnos a la hora que dispusiere el Regente, quien conversará con ellos dándoles alguna instrucción catequística sobre puntos de religión, del amor y respeto debido al Gobierno y a las Autoridades, a los padres, a los ancianos y a los pobres y desgraciados, y sobre todo acerca del deber de observar las instituciones vigentes. Después de esta conferencia, que deberá durar una hora, los alumnos acompañados del Regente y Ayudante pasarán a oir misa a la Yglesia que fuere más proporcionada, retirándose luego cada uno a su casa; si alguno de los Profesores fuese Sacerdote deberá decir la misa a los alumnos.

$\mathrm{Art}^{\circ}$. 30. Lo prescripto para los días de fiesta entera se observará en los de media fiesta por la mañana; por la tarde asistirán para los exámenes que determina el art ${ }^{\circ}$. 23, y no habiéndolos para el estudio de lo que Regente disponga. En estos días se les despachará una hora antes de lo acostumbrado en los demás.

Castigos

$\mathrm{Art}^{\circ}$. 31. Los castigos que han de imponerse son los siguientes:

$1^{\circ}$. Represión.

$2^{\circ}$. Plantón.

$3^{\circ}$. Aviso a los padres o encargados de la falta cometida que el Regente les pasará por medio del alumno que comisionare al efecto, bien por escrito o de palabra.

$4^{\circ}$. Detención en la Cátedra una o más horas.

$5^{\circ}$. Concurrencia a ella en días de asueto o vacaciones.

$6^{\circ}$. La expulsión. Es del Ayuntamiento decretarla y del Regente sólo el proponerla.

Ningún otro género de castigo podrán imponer los Profesores, y en designarlos observarán la mayor economía, cuidando de no castigar a muchos a un tiempo, y sobre todo de no amortiguar los sentimientos de delicadeza y honor, y que los jóvenes se acostumbren a mirar como última pena la pérdida o el menoscabo de su reputación. Los azotes, castigo de esclavos, inmoral, es indigno de hombres libres, las palmas, bofetadas y toda clase de golpes pueden dañar la salud, son depresivos, sirven sólo para embrutecer a los jóvenes, y en caso alguno será lícito a los Profesores hacer uso de ellos, pues quedan del todo proscriptos en este Reglamento.

Disposiciones generales

$\mathrm{Art}^{\circ}$. 32. Las antecedentes disposiciones quedan sujetas a las variaciones y reformas que el Ayuntamiento estime conveniente hacer. El Regente propondrá las que considere útiles.

"CUADERNOS DE ESTUDIOS GALLEGOS", Tomo XLIV, Fascículo 109, Santiago 1997. 
$\operatorname{Art}^{\circ}$. 33. El Ayuntamiento por medio de dos de sus individuos visitará la Cátedra una vez al mes, pudiendo hacerlo siempre que lo estime conveniente para informarse y mantener en vigor la disciplina y el buen orden" ${ }^{33}$.

\section{APÉNDICE NÚM. 5}

1842. Proposición presentada al Municipio por el regidor Jubes, instando a la corrección de algunas irregularidades observadas en el régimen de la Cátedra.

«Para el arreglo de la Cátedra de la Latinidad y evitar nuevas dificultades en lo sucesivo, propongo a V.S.S. los siguientes artículos, que considero de gran necesidad para que haya un método fijo, y no desorden.

$1^{\circ}$. Adoptar una papeleta que se entregue a todo el que sea admitido en la Cátedra, reproduciendo al Preceptor la prevención que se le hizo en 12 de Mayo de 1840 y 3 de Diciembre de 1841, de que no dé entrada a ninguno que no lleve este documento. En esta papeleta habrá de acreditarse el pago en depositaría del importe de la matrícula y retribución de un trimestre, y sucesivamente se irá anotando a continuación de la misma el pago de los trimestres según vayan venciendo.

$2^{\circ}$. Prohibir al Catedrático que bajo ningún pretexto reciba directamente de los alumnos retribución alguna, sino que todos han de satisfacerla en depositaría, para que el Ylustre Ayuntamiento tenga el debido conocimiento, y se expida a aquél el correspondiente libramiento del importe que le corresponda, pues así está acordado anteriormente de que no pueda percibir cantidad alguna que no vaya por este conducto.

$3^{\circ}$. Que se prevenga al Catedrático haga saber a los alumnos que satisfagan inmediatamente en depositaría las retribuciones vencidas desde la fecha del estado que aquél produjera, entre los cuales debe comprenderse a dn. Leopoldo Arteaga por los derechos de matrícula que aún no ha satisfecho.

$4^{\circ}$. Que el Catedrático dé conocimiento al Ayuntamiento del pase de los alumnos de la clase primera a la segunda, para poder exigirles el aumento de la retribución mensual que señala el reglamento.

$5^{\circ}$. Que se haga saber al Catedrático los acuerdos de 29 de septiembre y 13 de octubre del corriente, así como también que el goce de las retribuciones íntegras se enciende desde el 13 del actual» ${ }^{34}$.

\footnotetext{
${ }^{33}$ A.M.C., Instrucción Pública, 1839.
}

${ }^{34}$ A.M.C., Acuerdos, fols. 217-218.

"CUADERNOS DE ESTUDIOS GALLEGOS", Tomo XLIV, Fascículo 109, Santiago 1997. 